\title{
EFFECTIVENESS OF A REALTIME STUdENT RESPONSE SYSTEM FOR IMPROVING YEAR 1 ENGINEERING STUDENT ENGAGEMENT AND LEARNING
}

\author{
T. E. Doyle \\ Department of Electrical and Computer Engineering, McMaster University, Ontario Canada
}

doylet@mcmaster.ca

\section{INTRODUCTION}

The improvement of student engagement and learning are measures that can be difficult to quantify. Engineering 1 courses at McMaster University have integrated the usage of a realtime student response system to enhance the student learning experience. The realtime student response system permits students in a traditional lecture setting to wirelessly provide immediate enumerated feedback to questions presented by the instructor. The student response system provides immediate results of class answer distribution. While the execution of the system will require some lecture time, the results are improved test scores and increased lecture discussion. The author's observations and results of test scores will be presented and should be of interest to engineering educators considering a realtime student response system.

\section{BACKGROUND}

A realtime Student Response System (SRS), also known as a 'clicker', can be used in a lecture setting of any size to gauge student comprehension and to engage student interest. The SRS works by using wireless handheld devices that have several buttons which when pressed indicate the student answer to an instructor question. The response is typically multiple choice (A-E) and is collected by a wireless base station. The results are stored and typically available for immediate histogram display. As an example of the system, during the first lecture the students are asked a series of questions about their background in the course material and resources available to them, such as a personal computer. A question about the type of personal computer they have is presented in fig u re 1. What kind of computer do you have? A. Netbook

B. Laptop

C. Desktop

D. More than one of the above

E. None of the above

Figure 1: Example SRS question

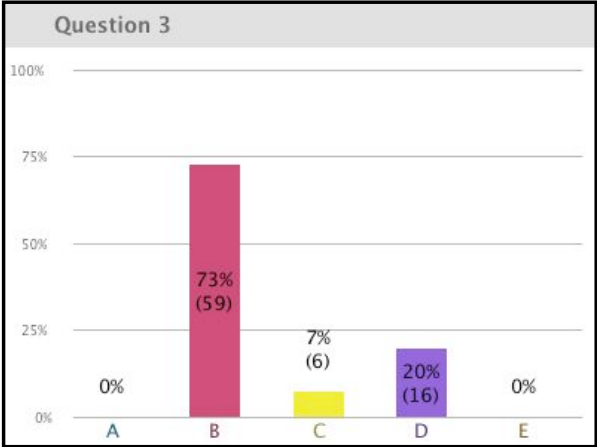

Figure 2: Example SRS response histogram

of concepts [1]. In addition it is has been shown to be an effective engagement tool that students enjoy [2].

At the start of the 2009 academic year the core set of first year Engineering courses (Design, Programming, and Professionalism) adopted an SRS system with the expectation of improving engagement and student learning. In addition, an attendance policy was established that would deduct a small percentage from the student final grade for missing more than 2 lectures.

\section{METHOD}

The author has run the first year engineering Design \& Graphics course for several years; however, due to course changes only the 2008 and 2009 academic years are directly comparable. Only the midterm and final exam assessment components are considered in this comparison.

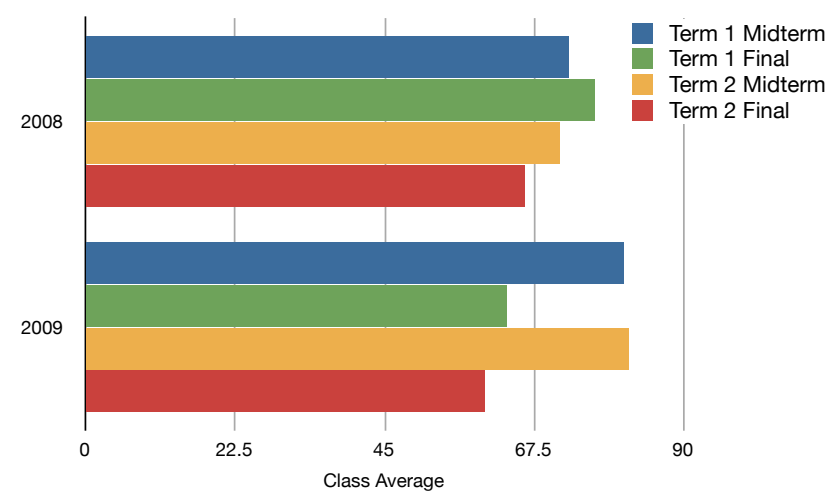

Figure 3: Academic year plotted against midterm and final exam average for Terms $1 \& 2$.

In the 2008 academic year, the course was delivered using traditional lecture, hand-sketching tutorials, and solid-modeling CAD laboratories. Lecture material covers background, theory, and examples with focus on a group dissection project in the second half of the term.

In the 2009 academic year, the course was run the same as the 2008 academic year, except the SRS was embedded into each lecture in the first half of the term. Question types were generally a multiple choice style with content that reviewed material from last lecture. Answer histogram result that illustrated some uncertainty were followed by an instructor led class discussion and review of the concept. The choice to focus the SRS implementation in the first half of the term was purely a function of pacing course material. Students were not informed of when the SRS would be used. Both midterm and final exam content was similar in content and question difficulty.

\section{RESULTS}

Results of the class midterm and final exam averages for academic years 2008 and 2009 are shown in figure 3. Midterm averages increased 5.0-8.2\%. Final exam averages fell 6.1-7.9\%.

The author observed increased student engagement and interaction through class discussion. Attendance was greater than $85 \%$ during the first half of term and decreased towards the end of term when the SRS was not used.

\section{DISCUSSION}

Truthfully the author was originally a skeptic of the SRS efficacy and was concerned that students may not use the system effectively. It was a surprise to compare the results of the 2008 and 2009 academic year midterms and a greater surprise to compare the final exam results.

Clearly there is a positive effect on student engagement and learning causing higher grades when the SRS is used to identify and discuss unclear concepts and to reinforce past topics. The trade-off is that the execution of the SRS will require lecture time that may not have been considered when preparing a course. In that regard, it is believed that the reduced final exam scores are the result of compressing material in the second half of term to keep pace with the previous year. In the 2010 academic year the author's course content will be redesigned, thus a direct comparison will not be possible; however, the SRS will be incorporated into lecture time with flexibility for discussion. In addition, early course performance may be a helpful indicator for identifying students that may be in need academic assistance.

For educators (especially the skeptics) considering an SRS, at the very least it will allow you to easily gauge student course participation when considering final grade assessment; however, I believe you will find it offers you and your students much more.

\section{REFERENCES}

1. Czekanski AJ, Roux DMP. Proc ASEE 2008 Ann Conf.

2. Caldwell JE. CBE Life Sci Edu 2007;6:9--20. 